\title{
GENÉTICA DE LA RESISTENCIA A Puccinia triticina Eriks EN TRIGOS CRISTALINOS INVERNALES
}

\author{
GENETICS OF RESISTANCE OF DURUM WINTER WHEAT TO Puccinia triticina Eriks
}

\author{
Laura M. Delgado-Sánchez ${ }^{1}$, Julio Huerta-Espino²*, Ma.-Cristina López-Peralta', \\ Ignacio Benitez-Riquelme ${ }^{1}$ y Eleodoro Hérnandez-Meneses ${ }^{1}$
}

\begin{abstract}
'Postgrado en Recursos Genéticos y Productividad-Genética, Colegio de Postgraduados. 56230, Montecillo, Texcoco, Estado de México. ${ }^{2}$ Campo Experimental Valle de México, Instituto Nacional de Investigaciones Forestales y Agropecuarias. Apdo. Postal 10. 56230, Chapingo, Edo. de México.
\end{abstract}

*Autor de correspondencia (J.huerta@cgiar.org)

\section{RESUMEN}

Entre 51 genotipos de trigo cristalino (T. turgidum var. durum) de habito invernal se identificó a Mirlo 26 y Elinia 48, como resistentes a la raza BBG/ BPC de Puccinia triticina E. (agente causal de roya de la hoja) en etapa de plántula. En la progenie de la cruza con el cultivar susceptible de primavera Atred se determinó que en Elinia 48 la resistencia fue condicionada por un gen dominante y otro recesivo mientras que en Mirlo 26 se debió a un gen recesivo. La cruza entre los dos genotipos resistentes no produjo progenie susceptible en la F2 ni en las familias F3, por lo que se sugiere la similitud de por lo menos un gen de resistencia en ambos progenitores. Mirlo 26 es susceptible mientras que Elinia 48 permaneció resistente a la raza BBB/BNJ virulenta a $L r 61$ identificada en el 2008, por lo que fue posible determinar que el gene recesivo identificado en Mirlo 26 es el gen que ambos progenitores tienen en común. En las poblaciones F2 y F3 de la cruza Mirlo 26 x Elinia 48 inoculadas con la raza BBB/BNJ virulenta sobre el gen recesivo la segregación fue de 3:1, que corresponde a la segregación para un gen dominante. Como resultado de las cruzas de los progenitores de invierno con el progenitor de primavera se dispone ahora genotipos de trigo cristalino de primavera que poseen el gen dominante y líneas con el gen recesivo.

Palabras clave: Triticum durum, Puccinia triticina, genes dominantes y recesivos, roya de la hoja del trigo.

\section{SUMMARY}

Among 51 durum winter wheat (T. turgidum var. durum) genotypes, Mirlo 26 and Elinia 48 were resistant to $P$. triticina race BBG/BPC at the seedling stage. From the progeny of the crosses with the susceptible spring cultivar Atred, it was determined that in Elinia 48 resistance was conferred by a dominant and by a recessive gene, while in Mirlo 26 resistance is provided by a recessive gene. The cross between the two resistant genotypes did not produce susceptible progeny in the F2 or F3 families, suggesting at least one common resistance gene is present in both parents. Mirlo 26 is susceptible to race BBB/BNJ identified in 2008 , while Elinia 48 remained resistant. Using this race, it was possible to determine that the recessive gene identified in Mirlo 26 is the gene that both parents have in common. To test these results, the progenies of Mirlo $26 \times$ Elinia 48 cross were inoculated with race BBB/BNJ, virulent to the recessive gene. In both populations F2 and F3 the segregation was 3:1, which corresponds to the segregation of a single dominant gene. As a result of the Winter $x$ Spring crosses, there are now spring durum wheats carrying the dominant gene and lines with the recessive gene.

Index words: Triticum durum, Puccinia triticina, recessive and dominant genes, leaf rust of wheat

\section{INTRODUCCIÓN}

El trigo (Triticum aestivum y T. turgidum var. durum) es un cereal ampliamente cultivado e importante para la dieta alimentaria y se considera un alimento completo y de alto aporte energético. De acuerdo con cifras del Servicio de Información Agroalimentaria y Pesquera (SIAP), en México el volumen de producción estimado de trigo durante los últimos diez años (2002-2012) fue de 37 millones de toneladas, de las cuales cerca de $85 \%$ se concentran en los estados de Sonora (35\%), Guanajuato (17.5\%), Baja California (11.5\%), Sinaloa (9.2\%), Michoacán (6.4\%) y Jalisco (4.4\%) (SIAP, 2015).

Uno de los problemas importantes a los que se ha enfrentado este cultivo es la roya de la hoja causada por Puccinia triticina E., una enfermedad ampliamente distribuida y devastadora en México y en el mundo (Huerta-Espino et al., 2011). Sus daños pueden causar pérdidas hasta de 84 $\%$ del rendimiento ya que sus infecciones tempranas provocan una disminución significativa en el número de granos por espiga, el peso hectolítrico y la calidad del grano (Singh y Huerta-Espino, 1997).

En México, la roya de la hoja es la más importante en trigos duros o cristalinos (Triticum turgidum var. durum) y la población de $P$. triticina es muy variable, compuesta por muchas razas, con distinta combinación de genes de avirulencia/virulencia (Huerta-Espino et al., 2011). En el año 2008 se identificaron las razas BBG/BPC y CBG/BPC, producto de la evolución de la raza BBG/BNC (Huerta-Espino et al., 2009), virulentas sobre las variedades de trigo Jupare C2001 y Banamichi C2004. Como producto de la evolución de la raza existente antes del año 2001 (Raza BBB/BNG) se identificó a la raza BBB/BNJ con virulencia para el gen Lr6 1 (Herrera-Foessel et al., 2008b).

El mejoramiento genético del trigo en México se basó en

Recibido: 10 de Julio del 2015

Aceptado: 05 de Febrero del 2016 
usar genes de resistencia de raza-específica o de plántula, cuya selección es relativamente fácil de llevar a cabo en generaciones tempranas (Mclntosch, 1992) al cruzar genotipos resistentes por susceptibles o resistentes por resistentes cuya herencia es de forma simple (HuertaEspino y Singh, 2000). Por lo general, las variedades que solo poseen un gen dominante de resistencia a la roya de la hoja pueden permanecer resistentes de 3 a 5 años bajo producción intensiva, antes de dejar de ser efectiva cuando el patógeno evoluciona en nuevas formas de virulencia (Singh y Dubin, 1997).

Muchos de los genotipos de trigos duros cultivados en México son resistentes a la roya de la hoja en estado de plántula y planta adulta debido a la presencia del gen Lr74a para el cual aún no existe virulencia entre las razas que preferentemente atacan a trigos cristalinos (Huerta Espino et al., 2010).

Por consiguiente, es fundamental identificar nuevos genes de resistencia efectivos a la roya de la hoja del trigo en genotipos resistentes a la raza BBG/BN, para generar así diversidad genética y contribuir a disminuir las pérdidas en rendimiento y la producción con futuras variedades de trigo cristalino.

Los objetivos de esta investigación fueron explorar la resistencia a la roya de la hoja en estado de plántula dentro de un grupo selecto de trigo cristalino de invierno y examinar el tipo de herencia de esta característica en dos nuevas fuentes de resistencia diferentes a las disponibles para la raza BBG/BPC de roya de la hoja.

\section{MATERIALES Y MÉTODOS}

\section{Material genético de trigo cristalino}

Se estudiaron 51 trigos cristalinos de hábito invernal provenientes de diferentes países de los cuales se seleccionaron dos por su resistencia a la raza BBG/BPC que se cruzaron con el progenitor susceptible Atred para obtener plantas F1, F2 y familias F3 respectivamente. También se hicieron cruzas entre los progenitores invernales resistentes las cuales se avanzaron hasta obtener familias F3.

\section{Condiciones de crecimiento}

Los 51 genotipos de trigo cristalinos invernales, las plantas F2, los progenitores resistentes y susceptible y las familias F3 se sembraron en charolas de plástico de $20 \mathrm{~cm}$ de largo $\times 30 \mathrm{~cm}$ de ancho $\times 6 \mathrm{~cm}$ de profundidad, en una mezcla de sustrato (tierra + turba "peat moss", proporción 1:1), al marcar 48 orificios de $1 \mathrm{~cm}$ de diámetro $\times 2 \mathrm{~cm}$ de profundidad con una plancha de acero de 8 hileras y 6 co- lumnas. Se sembraron diez semillas de cada uno de los genotipos. Las charolas se etiquetaron y colocaron en invernadero a una temperatura de $18 \pm 2{ }^{\circ} \mathrm{C}$ durante la noche y $20 \pm 2{ }^{\circ} \mathrm{C}$ en el día. Las plántulas se fertilizaron con la fórmula 17-17-17 (N-P-K) disuelta en agua al aplicar 125 $\mathrm{ml}$ por charola.

\section{Razas del patógeno}

Se usaron dos razas de $P$. triticina, BBG/BPC y BBB/BNJ según la nomenclatura de Singh (1991), a las que se adicionó una sexta letra correspondiente al juego de diferenciales con los genes de resistencia $L r 74 a, L r 28, L r 67$ y $L r 72$, para así distinguir la raza BBB/BNJ virulenta a $L r 61$ de la raza BBB/BNG que es avirulenta. La fórmula de avirulencia/virulencia para BBG/BPC es: LrT, Lr2a, Lr2b, Lr2c, Lr3, Lr3bg, Lr3ka, Lr9, Lr73, Lr74a, Lr75, Lr76, Lr77, Lr78, Lr79, Lr21, Lr24, Lr25, Lr26, Lr28, Lr29, Lr30, Lr32, Lr35, Lr36, Lr61 /Lr10, Lr17, Lr12, Lr74b, Lr20, Lr23, Lr27, Lr37, Lr33, $L r 72$, mientras que para la raza BBB/BNJ es: $L r 7, L r 2 a, L r 2 b$, Lr2c, Lr3, Lr3bg, Lr3ka, Lr9, Lr17, Lr13, Lr74a, Lr75, Lr76, Lr17, Lr18, Lr19, Lr27, Lr24, Lr25, Lr26, Lr29, Lr30, Lr32, Lr35, Lr36, Lr72/Lr70, Lr74b, Lr20, Lr23, Lr28, Lr33, Lr67.

\section{Procedimiento de inoculación}

La inoculación se realizó 10 d después de la siembra, cuando se extendió por completo la hoja primaria, mediante aspersión foliar de las plántulas con una suspensión de urediniosporas en aceite mineral Sotrol®170 (Chevron Phillips Chemical Company LP) de la raza BBG/BPC y a un segundo juego de todos los genotipos con la raza BBB/ BNJ. Una vez que las plantas se inocularon, se dejaron secar por 20 min y luego se colocaron por 16 h en una cámara húmeda con humificador (Hydrofogger, H2OTEK, Monterrey, México) a 100 \% de humedad relativa Posteriormente las plántulas se trasladaron al invernadero donde se mantuvieron entre 20 y $24^{\circ} \mathrm{C}$ de temperatura (Figura 1), hasta la aparición de los signos de la enfermedad.

\section{Características evaluadas}

El tipo de infección fue evaluado a los 9 y 10 d después de la inoculación, mediante la escala de 0 a 4 propuesta por Roelfs et al. (1992). Los tipos de infección (TI) 3 y 4 se consideraron susceptibles y los TI 0, 1 y 2 , resistentes. Se contabilizó el número de plántulas resistentes y el número de plántulas F2 susceptibles así como las cantidades de familias F3 resistentes, susceptibles y segregantes. Después de la inoculación en plántula, se seleccionaron plantas $\mathrm{F} 2$ resistentes con hábito de primavera, las cuales se avanzaron para obtener familias F3 que también fueron inoculadas con los procedimientos previamente descritos. 


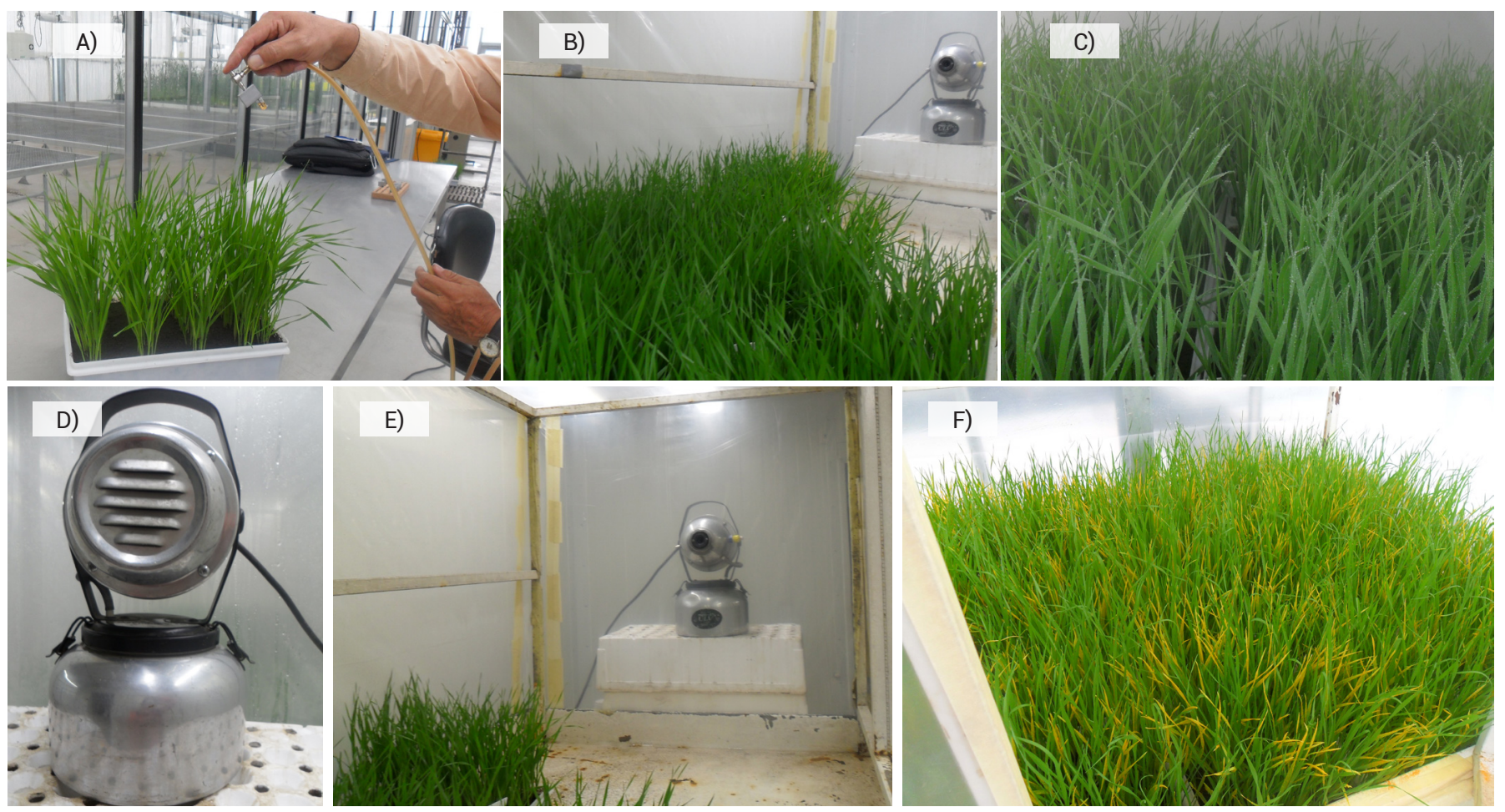

Figura 1. Proceso de inoculación de Puccinia triticina: A) Inoculación de la roya en charolas con 48 orificios; B) Cámara de humidificación; C) Inicio de rocío; D) Humificador (Hydrofogger); E) Plantas después de 16 h de rocío; F) Aparición de signos de la roya de la hoja.

\section{Análisis estadístico}

Las frecuencias observadas y esperadas se compararon mediante la prueba de Ji-cuadrada ( $\chi 2$ ). El valor de tablas y la significancia se determinó de acuerdo con la $\chi 2$ que obtuvieron las proporciones de las F2 o F3 de cada cruza. Para el valor de tablas se usaron $n-1$ grados de libertad, en donde $n$ es el número de grupos de clasificación de familias F2 o F3 (Infante-Gil y Zárate de Lara, 1990).

\section{RESULTADOS Y DISCUSIÓN}

De los 51 genotipos de trigos cristalinos de hábito invernal evaluados en etapa de plántula Mirlo 26 y Elinia 48 resultaron resistentes a la raza de roya BBG/BPC y solo Elinia 48 fue resistente a la raza BBB/BNJ (Figura 2), lo cual permitió seleccionar genotipos resistentes. En la cruza de las variedades Atred x Mirlo 26 la proporción de plantas resistentes y susceptibles fue de 1:3 lo que indica que la resistencia en Mirlo 26 a la raza BBG/BPC es conferida por un gen recesivo (Cuadro 1). En la progenie de la cruza entre Atred x Elinia 48, inoculada con la misma raza, la proporción de plantas resistentes y susceptibles fue 13:3 indicando que la resistencia en Elinia 48 es conferida por un gen dominante y un gen recesivo.
Al inocular las plantas F2 de la cruza Atred x Mirlo 26 con la raza BBB/BNJ no se encontraron plantas resistentes lo que indica que el gene recesivo identificado en Mirlo 26 es inefectivo a la raza BBB/BNJ, mientras que en la cruza Atred y Elinia 48 la proporción fenotípica 3:1 señala la presencia de un gen de resistencia dominante en Elinia 48 que es efectivo a ambas razas de roya de la hoja usadas en el estudio, lo que se confirmó al evaluar las familias F3 entre la cruza Mirlo 26 x Elinia 48. En la progenie de la cruza Elinia 48 x Mirlo 26 inoculada con la raza BBG/BPC no se observaron plantas susceptibles, lo indica que ambos progenitores tienen un gen de resistencia en común. Sin embargo, al evaluar la progenie con la raza BBB/BNJ los datos mostraron una segregación que se ajusta a 1:2:1 que indica presencia de un gen dominante, y por lo tanto se puede inferir que el gen en común entre Mirlo 26 y Elinia 48 es el gen recesivo (Cuadro 2).

Entre las plantas resistentes a la raza BBG/BPC, obtenida del cruzamiento de los genotipos Atred x Mirlo 26 y Atred $x$ Elinia 48 se seleccionaron 135 plantas (Cuadro 3) las cuales fueron evaluadas primero con la raza BBG/BPC y posteriormente con la raza BBB/BNJ (Cuadro 3), lo que permitió identificar genotipos con hábito de primavera y resistentes a la raza $\mathrm{BBG} / \mathrm{BPC}$. 


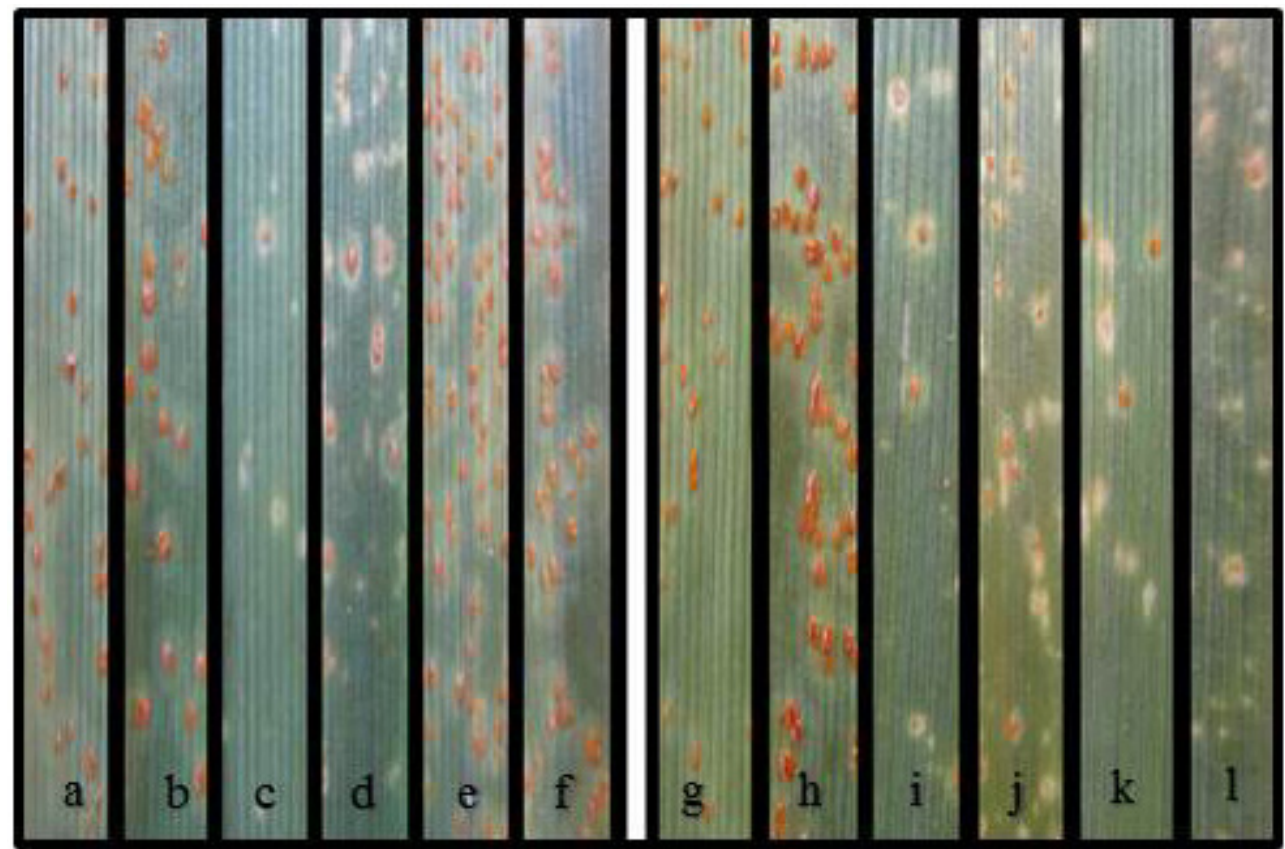

Figura 2. Clasificación de los genotipos por su respuesta a la raza BBB/BNJ de Puccinia triticina en var. Atred: (a) Primera hoja, (b) Segunda hoja; en var. Elinia 48: (c) Primera hoja, (d) Segunda hoja; en var. Mirlo 26: (e) Primera hoja, (f) Segunda hoja. Para la raza BBG/BP. en var. Atred: (g) Primera hoja, (h) Segunda hoja; en var. Elinia 48 (i) Primera hoja, (j) Segunda hoja; en var. Mirlo 26: (k) Primera hoja, (l) Segunda hoja.

Cuadro 1. Número de plantas F2 resistentes y susceptibles observadas frente a las razas BBG/BPC y BBB/BNJ de roya de la hoja.

\begin{tabular}{lcccccc}
\hline \multirow{2}{*}{ Cruza } & \multirow{2}{*}{ Total de plantas } & \multicolumn{2}{c}{ Número de plantas Observadas } & $\begin{array}{c}\text { Proporción } \\
\text { fenotípica }\end{array}$ & $\chi^{2}$ & Probabilidad \\
\cline { 3 - 7 } & & Resistentes & Susceptibles & Raza BBG/BPC & & \\
Atred x Mirlo 26 & 218 & 51 & 167 & $1: 3$ & 0.27 & 0.90 \\
Atred x Elinia 48 & 154 & 127 & 27 & $13: 3$ & 0.13 & 0.90 \\
Elinia 48 x Mirlo 26 & 135 & 135 & - & - & & \\
& & & Raza BBB/BNJ & & \\
Atred x Mirlo 26 3F1 & 100 & 0 & 100 & $3: 1$ & 0.05 & 0.90 \\
Atred x Elinia 48 2F1 & 100 & 74 & 26 & $3: 1$ & 0.016 & 0.90 \\
Mirlo 26 x Elinia 48 & 123 & 93 & 30 & \\
\hline
\end{tabular}

Cuadro 2. Número de familias F3 de la cruza Elinia 48 x Mirlo 26 observadas frente a la raza BBB/BNJ de roya de la hoja.

\begin{tabular}{|c|c|c|c|c|c|c|c|}
\hline \multirow{2}{*}{ Cruza z } & \multirow{2}{*}{ Total de familias } & \multicolumn{3}{|c|}{ No. de familias observadas } & \multirow{2}{*}{ Proporción fenotípica } & \multirow{2}{*}{$x^{2}$} & \multirow{2}{*}{ Probabilidad } \\
\hline & & Resistentes & Susceptibles & Segregantes & & & \\
\hline $\begin{array}{l}\text { Elinia } 48 x \\
\text { Mirlo } 26\end{array}$ & 135 & 37 & 64 & 34 & 1:2:1 & 0.5 & 0.90 \\
\hline
\end{tabular}


Cuadro 3. Tipo de infección de genotipos de primavera de las cruzas Atred x Mirlo 26 y Atred x Elinia 48 en estado de plántula frente a las razas BBG/BPC y BBB/BNJ.

\begin{tabular}{|c|c|c|c|c|}
\hline Ent. & Origen & Cruza & BBG/BPC & $\mathrm{BBB} / \mathrm{BNJ}$ \\
\hline 1 & $1 \mathrm{GH}$ & Atred $\times$ Mirlo 26 & $X=^{+}$ & $3+$ \\
\hline 2 & $3 \mathrm{GH}$ & AtredxMirlo 26 & $X=$ & $3+$ \\
\hline 3 & $4 \mathrm{GH}$ & AtredxMirlo 26 & $x=$ & $3+$ \\
\hline 4 & $10 \mathrm{GH}$ & AtredxMirlo 26 & $x=$ & $3+$ \\
\hline 5 & $15 \mathrm{GH}$ & AtredxMirlo 26 & $X=$ & 4 \\
\hline 6 & $16 \mathrm{GH}$ & AtredxMirlo 26 & $; 1$ & 4 \\
\hline 7 & $17 \mathrm{GH}$ & AtredxMirlo 26 & $x=$ & 4 \\
\hline 8 & $18 \mathrm{GH}$ & AtredxMirlo 26 & $x=$ & 4 \\
\hline 9 & $20 \mathrm{GH}$ & AtredxMirlo 26 & $; 1-$ & 4 \\
\hline 10 & $21 \mathrm{GH}$ & AtredxMirlo 26 & $x=$ & 4 \\
\hline 11 & $22 \mathrm{GH}$ & AtredxMirlo 26 & $X=$ & 4 \\
\hline 12 & $3 \mathrm{GH}$ & AtredxElinia 48 & $x$ & $x$ \\
\hline 13 & $6 \mathrm{GH}$ & AtredxElinia 48 & $5 \mathrm{PX}, 3 \mathrm{P} 3+-^{+}$ & $1 h X+, 2 h X-++$ \\
\hline 14 & $7 \mathrm{GH}$ & AtredxElinia 48 & $x$ & 6PX, 2P3+ \\
\hline 15 & $9 \mathrm{GH}$ & AtredxElinia 48 & 7PX, P3+ & $1 h X+, 2 h x$ \\
\hline 16 & $10 \mathrm{GH}$ & AtredxElinia 48 & $1 P X$ & $2 \mathrm{PX}$ \\
\hline 17 & $11 \mathrm{GH}$ & AtredxElinia 48 & $x$ & $x$ \\
\hline 18 & $15 \mathrm{GH}$ & AtredxElinia 48 & $x$ & 8PX, 1P3+ \\
\hline 19 & $18 \mathrm{GH}$ & AtredxElinia 48 & $X=$ & $x$ \\
\hline 20 & $21 \mathrm{GH}$ & AtredxElinia 48 & $x$ & $3 \mathrm{P} 4$ \\
\hline 21 & $22 \mathrm{GH}$ & AtredxElinia 48 & $x$ & $1 h x+, 2 h x$ \\
\hline 22 & $23 \mathrm{GH}$ & AtredxElinia 48 & $1 \mathrm{hX}, 2 \mathrm{hX}=$ & $1 \mathrm{hX}, 2 \mathrm{hX}=$ \\
\hline 23 & $24 \mathrm{GH}$ & AtredxElinia 48 & $3+$ & 4 \\
\hline 24 & $27 \mathrm{GH}$ & Atred Elinia 48 & $x$ & $x$ \\
\hline 25 & $28 \mathrm{GH}$ & AtredxElinia 48 & $1 \mathrm{hX}+, 2 \mathrm{hX}=$ & $1 \mathrm{hX}+, 2 \mathrm{hX}=$ \\
\hline 26 & $31 \mathrm{GH}$ & AtredxElinia 48 & $x$ & $x$ \\
\hline 27 & $32 \mathrm{GH}$ & AtredxElinia 48 & $x$ & $x$ \\
\hline 28 & $34 \mathrm{GH}$ & AtredxElinia 48 & 7PX, 1P3+ & $x$ \\
\hline 29 & $37 \mathrm{GH}$ & AtredxElinia 48 & $x$ & $x$ \\
\hline 30 & $41 \mathrm{GH}$ & AtredxElinia 48 & $6 \mathrm{PX}, 3 \mathrm{P} 4$ & $x$ \\
\hline 31 & $42 \mathrm{GH}$ & AtredxElinia 48 & $x$ & $x$ \\
\hline \multicolumn{2}{|c|}{ Testigo susceptible } & Atred & 4 & 4 \\
\hline \multicolumn{2}{|c|}{ Prog. resistente } & Elinia 48 & $x$ & $x$ \\
\hline \multicolumn{2}{|c|}{ Prog. resistente } & Mirlo 26 & $x$ & 4 \\
\hline
\end{tabular}

$\bar{X}=, X, 3$ y 4: Tipos de infección de acuerdo con Roelfs et al. (1992). ${ }^{+}$Familias segregantes con plantas resistentes; ${ }^{\text {t+ }}$ Susceptibles con tipo de infección diferente;1h: Tipo de infección en la primera hoja; 2h: Tipo de infección en la segunda hoja. 
El porcentaje de genotipos resistentes en etapa de plántula a la roya de la hoja en un grupo de hábito invernal solo representó alrededor de $4 \%$, lo que coincide con los bajos niveles de resistencia a la roya de la hoja en trigos harineros de invierno. Las razas de roya de la hoja que afectan a trigos cristalinos son virulentas para la mayoría de genotipos de trigo de este tipo. Una sola raza vulneró la resistencia de más de $85 \%$ del germoplasma disponible en el CIMMYT (Singh et al., 2004), que incluyó a todas las variedades cultivadas en México.

Zhang y Knott (1990) reportaron la presencia de un gen dominante ( $L r 17)$ en la variedad Quilafen en sus estudios con ocho cultivares de trigo cristalino de primavera de diversos orígenes resistentes a roya de la hoja. Genes dominantes y recesivos, o combinaciones de ellos, confirieron resistencia en etapa de plántula en estos materiales, lo que indica la presencia de genotipos resistentes a roya de la hoja de trigo cristalino de hábito invernal entre los trigos criollos disponibles en Europa y en el banco de germoplasma del CIMMYT. La resistencia en Elinia 48 a la raza BBG/ BP identificada en este estudio, probablemente proviene de progenitores de primavera (Herrera-Foessel et al., 2014).

De los genes de resistencia identificados y catalogados en trigo (McCallum et al., 2011) solo Lr30 ha sido descrito como recesivo; los demás, son reportados como dominantes o parcialmente dominantes (McIntosh et al., 1995). Sin embargo, Fitzgerald et al., (1957) encontraron que la resistencia a roya de la hoja fue condicionada por dos genes recesivos complementarios que confirieron resistencia a la raza 65, los cuales fueron designados como Lr7 y Lr8 que son heredados de forma independiente. No se dispone de progenitores o genotipos portadores de estos genes.

El gen recesivo que confiere la resistencia en Mirlo 26 en respuesta a la raza BBG/BPC es inefectivo para la raza $\mathrm{BBB} / \mathrm{BNJ}$, aspecto que limita su uso. Mientras esta raza siga predominando en México, el gen recesivo identificado podrá ser útil siempre que esté acompañado por el gen Lr72 presente en las variedades Altar C84 y Atil C2000 (Herrera-Foessel et al., 2014), u otro gen efectivo tanto a BBG/ $\mathrm{BPC}$ como a BBN/BNJ.

Aguilar et al. (2000), al determinar la genética de resistencia en trigos sintéticos hexaploides (T. turgidum $\times T$. tauschii), encontraron que dos y un gen dominante estuvieron involucrados. Mientras que Statler (1972) reportó dos genes recesivos como responsables de la resistencia en Leeds. En ocho genotipos de trigo cristalino resistentes Zhang y Knott (1990) reportaron un gen dominante y un recesivo en Stewart 63, un recesivo en Loyd, y un dominante y un recesivo en Medora y Vic, como lo encontrado en Elinia 48 para la raza BBG/BPC.
La resistencia conferida por un gen dominante es más común tanto en trigos harineros como en los cristalinos como es el caso de Lr10 (Aguilar et al., 2000), Lr74a (Herrera-Foessel et al., 2008a), Lr74b y 17 (Zhang et al., 2008), Lr23 (Aguilar et al., 1999), Lr61 (Herrera-Foessel et al., 2008b), Lr72 (Herrera- Foessel et al., 2014), y otros genes no catalogados que se han identificados en genotipos de trigo cristalino colectados en Oaxaca (Huerta-Espino et al., 2011).

El gen dominante identificado en Elinia 48, efectivo no solo a las razas BBG/BPC y BBB/BNJ sino también a las otras razas de roya virulentas sobre trigos cristalinos identificadas en México y en conjunto con otros genes, podrían proveer de mayores niveles de resistencia en los trigos cristalinos cultivados en este país.

Como resultado de las cruzas del trigo susceptible de primavera con los progenitores resistentes de hábito invernal, fue posible identificar genotipos resistentes con hábito de primavera, que poseen un buen tipo agronómico. Estas líneas pueden usarse como fuentes de resistencia a roya de la hoja en un programa de mejoramiento y emplear el gen dominante efectivo para la raza de roya más común ahora en México (BBG/BPC) en combinación con otros genes.

\section{CONCLUSIONES}

En trigos cristalinos la resistencia de la roya de la hoja está determinada por un gen recesivo en Mirlo 26, y en Elinia 48 por uno dominante y uno recesivo a la raza BBG/ BPC. El gen recesivo en Mirlo 26 es similar al gen recesivo en Elinia 48, el cual es inefectivo a la raza BBB/BNJ. Se obtuvieron genotipos de primavera que poseen el gen dominante y genotipos con el gen recesivo de resistencia.

\section{BIBLIOGRAFÍA}

Aguilar R. V. H., R. P. Singh y J. D. Molina G. (1999) Genética de la resistencia a la roya de la hoja de cuatro trigos sintéticos hexaploides. Revista Fitotecnia Mexicana 22:215-226.

Aguilar R. V. H., R. P. Singh R., J. D. Molina G. y J. Huerta-Espino (2000) Herencia de la resistencia de la roya de la hoja en cuatro trigos sintéticos hexaploides. Agrociencia 34:235-245.

Fitzgerald P. J., R. M. Caldwell and 0. E. Nelson Jr. (1957) Inheritance of resistance to certain races of leaf rust of wheat. Agronomy Journal 49:539-543.

Herrera-Foessel S. A., R. P. Singh, J. Huerta-Espino, J. Yuen and A. Djurle (2003) Diversity of resistance to leaf rust in five CIMMYT germoplasm derived durum wheats. In: Proceedings of the Tenth International Wheat Genetics Symposium 1-6. September 2003. Paestum, Italy. Vol. 1:361-363.

Herrera-Foessel S. A., R. P. Singh, J. Huerta-Espino, M. William, V. Garcia, A. Djurle and J. Yuen (2008a) Identification and molecular characterization of leaf rust resistance gene Lr14a in durum wheat. Plant Disease 92:469-473.

Herrera-Foessel S. A., R. P. Singh, J. Huerta-Espino, H. M. William, A. Djurle and J. Yuen (2008b) Molecular mapping of a leaf rust resistance gene on the short arm of chromosome $6 \mathrm{~B}$ of durum wheat. 
Plant Disease 92:1650-1654.

Herrera-Foessel S. A., J. Huerta-Espino, V. Calvo-Salazar, C. X. Lan and R. P. Singh (2014) Lr72 confers resistance to leaf rust in durum wheat cultivar 'Atil C2000'. Plant Disease 98:631-635.

Huerta-Espino J. y R. P. Singh (2000) Las royas de trigo. In: El Trigo de Temporal en México. H. E. Villaseñor M. y E. Espitia R. (eds.) SAGARPA, INIFAP. CIP-CENTRO y CEVAMEX, México. pp:231251.

Huerta-Espino J., R. P. Singh, S. A. Herrera-Foessel, B. Pérez-López and P. Figueroa-López (2009) First detection of virulence in Puccinica triticina to resistance genes Lr27 + Lr31 present in durum wheat in México. Plant Disease 93:110.

Huerta-Espino J., R. P. Singh, S. Germán, B. D. McCallum, R. F. Park, W. Q. Chen, S. C. Bhardwaj and H. Goyeau (2011) Global status of wheat leaf rust caused by Puccinia triticina. Euphytica 179:143-160.

Huerta Espino J., R. P. Singh, H. E. Villaseñor M., E. Solís M., E. Espitia R. y S. G. Leyva M. (2010) Transferencia del gen Lr14a de trigos harineros a trigos cristalinos y expresión de la resistencia a roya de la hoja. Revista Fitotecnia Mexicana 33:29-36.

Huerta Espino J., M. E. Rodríguez Contreras, M. F. Rodríguez García, H. E. Villaseñor Mir, S. G. Leyva Mir y E. Espitia Rangel (2011) Variación genética de la resistencia a Puccinia triticina E. en trigos duros de Oaxaca, México. Revista Fitotecnia. Mexicana 34:35-41.

Infante-Gil S. y G. P. Zárate de Lara (1990) Métodos Estadísticos. Ed. Trillas, México. $643 p$

McCallum B., C. Hiebert, J. Huerta-Espino and S. Cloutier (2011) Wheat leaf rust. In: Disease Resistance in Wheat. I. Sharma (ed.). CAB International 2012. pp:33-62.

McIntosh R. A. (1992) Close genetic linkage of genes conferring adultplant resistance to leaf rust and stripe rust in wheat. Plant $\mathrm{Pa}$ - thology 41:523-527.

McIntosh R. A. C. R. Wellings and R. F. Park (1995) Wheat Rusts: An Atlas of Resistance Genes. CSIRO Australia Kluwer Academic Publishers, London. $200 \mathrm{p}$

Roelfs A. P., R. P. Singh y E. E. Saari (1992) Las Royas del Trigo: Conceptos y Métodos para el Manejo de esas Enfermedades. México, D.F. CIMMYT. 81 p.

SIAP, Servicio de Información Agroalimentaria y Pesquera (2015) www.siap. sagarpa.gob.mx (Abril 2015).

Singh R. P. (1991) Pathogenicity variations of Puccinia recondita f. sp. tritici and P. graminis f. sp. tritici in wheat-growing areas of Mexico during 1988 and 1989. Plant Disease 75:790-794

Singh R. P. and H. J. Dubin (1997) Sustainable control of wheat diseases Mexico. In: Primer Simposio Internacional de Trigo, Memorias.7-9 de abril de 1997. Cd. Obregón, Sonora. Mexico pp:93102

Singh R. P. and J. Huerta-Espino (1997) Effect of leaf rust resistance gene Lr34 on grain yield and agronomic traits of spring wheat. Crop Science 37:390-395.

Singh R. P., J. Huerta-Espino, P. Figueroa L. and W. Pfeiffer (2004) Occurrence and impact of a new leaf rust trace on durum wheat in the Northwestern Mexico during 2001-2002. Plant Disease 87:703-708

Statler G. D. (1972) Inheritance of leaf rust resistance in Leeds durum wheat. Crop Science 13:116-117.

Zhang H. and D. R. Knott (1990) Inheritance of leaf rust resistance in durum wheat. Crop Science 30:1218-1222.

Zhang J. X., R. P. Singh, J. A. Kolmer, J. Huerta-Espino and A. Anderson (2008) Inheritance of leaf rust resistance in CIMMYT Wheat Weebill 1. Crop Science 48:1037-1047. 